University of South Carolina

Scholar Commons

1990

\title{
Predicted Secondary Current Distributions for Linear Kinetics in a Modified Three-Dimensional Hull Cell
}

\author{
F. A. Jagush \\ Texas A \& M University - College Station \\ Ralph E. White \\ University of South Carolina - Columbia, white@cec.sc.edu \\ William E. Ryan
}

Follow this and additional works at: https://scholarcommons.sc.edu/eche_facpub

Part of the Chemical Engineering Commons

\section{Publication Info \\ Journal of the Electrochemical Society, 1990, pages 1848-1851.}

(C) The Electrochemical Society, Inc. 1990. All rights reserved. Except as provided under U.S. copyright law, this work may not be reproduced, resold, distributed, or modified without the express permission of The Electrochemical Society (ECS). The archival version of this work was published in the Journal of the Electrochemical Society.

http://www.electrochem.org/

DOI: $10.1149 / 1.2086815$

http://dx.doi.org/10.1149/1.2086815

This Article is brought to you by the Chemical Engineering, Department of at Scholar Commons. It has been accepted for inclusion in Faculty Publications by an authorized administrator of Scholar Commons. For more information, please contact digres@mailbox.sc.edu. 
density; and, consequently, should prevent overheating or blistering of the membrane and damage to the membrane due to nonuniform current distributions and impurities.

\section{Summary}

TOPAZ3D (5) can be used to determine current density distributions in electrolysis cells as demonstrated for a section of a bipolar, chlor-alkali membrane cell. The current density for the electrolysis cell considered here was about $0.62 \mathrm{~A} / \mathrm{cm}^{2}$. The resulting current density in a typical boss portion of the cell was about $25 \mathrm{~A} / \mathrm{cm}^{2}$. However, because of the highly conductive electrodes used in the cell, the current density distribution through the membrane portion of the cell was found to be essentially uniform.

\section{Acknowledgment}

The authors acknowledge gratefully that this work was supported by the Texas Applied Science and Technology Laboratories of Dow Chemical U.S.A.

Manuscript submitted June 26, 1989; revised manuscript received Dec. 8, 1989.

Dow Chemical U.S.A. assisted in meeting the publication costs of this article.

\section{LIST OF SYMBOLS}

i current density vector, $\mathrm{A} / \mathrm{cm}^{2}$

$i_{\mathrm{s}, \mathrm{i}} \quad$ current density on surface segment $i, \mathrm{~A} / \mathrm{cm}^{2}$

$n_{x}, n_{y}, n_{z}$ dimensionless directional cosines

$x, y$, and $z$ coordinates in $\mathrm{cm}$

\section{Greek}

$\kappa_{x}, \kappa_{y}, \kappa_{z} \quad$ specific conductivities, $\Omega^{-1} \mathrm{~cm}^{-1}$

$\Phi$ potential, $\mathrm{V}$

$\Phi_{\text {ref }} \quad$ reference potential $\left(\Phi_{\text {ref }}=1 \mathrm{~V}\right.$ here), $\mathrm{V}$

$\phi \quad$ dimensionless potential

$\Omega \quad$ region of interest

$\Gamma_{i} \quad$ surface segment $i$ on $\Omega$

\section{REFERENCES}

1. G. J. Morris, in "Modern Chlor Alkali Technology," Vol. 4, K. Wall, Editor, Ellis Horwood Limited, West Sussex, England (1989).

2. J. T. Keating, in "Electrochemical Engineering in the Chlor-Alkali and Chlorate Industries," PV 88-2, F. Hine, W. B. Darlington, R. E. White, and R. D. Varjian, Editors, p. 311, The Electrochemical Society Softbound Proceedings Series, Pennington, NJ (1988).

3. E. C. Dimpault-Darcy and R. E. White, This Journal, $135,656(1988)$

4. A. B. Shapiro, "TOPAZ2D-A Two-Dimensional Finite Element Code for Heat Transfer Analysis, Electrostatic, and Magnetostatic Problems," University of California, Lawrence Livermore National Laboratory, Report No. UCID-20824 (1986).

5. A. B. Shapiro, "TOPAZ3D-A Three-Dimensional Finite Element Heat Transfer Code," University of California, Lawrence Livermore National Laboratory, Report No. UCID-20484 (1985).

6. J. Deconinck, D. Maggetto, and J. Vereechken, This Journal, 132, 2960 (1985)

7. M. Simek, and I. Rousar, J. Applied Electrochem., 18, 96 (1988).

8. R. Alkire and T. Bergh, This Journal, 125, 1981 (1978).

9. M. Matlosz, C. Creton, C. Clerc, and D. Landolt, ibid., 134, 3015 (1987).

10. N. G. Zamani, J. M. Chuang, and C. C. Hsiung, Int. J. Num. Methods Eng., 24, 1479 (1987).

11. N. G. Zamani, J. F. Porter, and A. A. Mufti, ibid., 23, 1295 (1986)

12. R. Morris and W. Smyrl, AIChE J., 34, 723 (1988).

13. G. J. E. Morris, J. R. Pimlott, R. N. Beaver, H. D. Dang, and S. Grosshandler, U.S. Pat. 4,604,171 (1986).

14. D. W. Stillman and J. O. Hallquist, "INGRID: A ThreeDimensional Mesh Generator for Modeling Nonlinear Systems," University of California, Lawrence Livermore National Laboratory, Report No. UCID20506 (1985).

\title{
Predicted Secondary Current Distributions for Linear Kinetics in a Modified Three-Dimensional Hull Cell
}

\author{
F. A. Jagush* and R. E. White** \\ Department of Chemical Engineering, Texas A\&M University, College Station, Texas 77843-3122 \\ William E. Ryan** \\ Texas Instruments, Incorporated, Dallas, Texas 75265
}

Current density distribution is an important consideration for those involved in designing electrochemical systems and electroplating systems in particular. Although it is important, the common practice in industry is to use trial and error to determine designs that optimize current density distributions in electroplating. The purpose of this paper is to illustrate the use of the finite element method (FEM) to predict three-dimensional current density distributions.

Two-dimensional FEM has been used successfully in modeling corrosion systems (1-8), electrolyzers (9), and three-phase cells $(10,11)$. Alkire, Bergh, and Sani (12) were among the first to apply the finite element method to electrochemical potential distribution problems. They studied the shape changes in electrodes during electrodeposition. The system studied was composed of a cathode made with parallel metal strips separated by an insulator and an anode at a fixed distance. Transient analysis using the FEM provided a time history of cathode shape during deposition. Finite element results agreed to within $2-5 \%$ of the analytical solutions. Micromechanics of multilayer printed

\footnotetext{
* Electrochemical Society Student Member.
}

*** Electrochemical Society Active Member. wiring boards have also been studied using the FEM. Lee et al. (13) studied the thermomechanical strain in printed wiring boards. They constructed a finite element model for both plated through-holes and buried via structures to calculate the stresses in the copper barrel and at the via junctions.

An illustrative example of the use of the FEM in electroplating is given by Matlosz et al. (14). In their paper they compared the finite element solution of current densities in a Hull cell to those obtained experimentally and through the boundary element method (BEM). The Hull cell is used commonly for visual measurement of the quality of electrochemical solutions (15). Most plating solutions are tested using a current of $2 \mathrm{~A}$ and a plating time of $10 \mathrm{~min}$ (16). The slanted cathode used in this cell allows for a range of current densities, and how much of it is covered with deposit will depend on the quality of the solution.

TOPAZ2D (17) and TOPAZ3D (18) are finite element codes designed specifically for heat transfer problems. White et al. (19) used TOPAZ3D to predict current and potential distributions in a bipolar chlor-alkali membrane cell. They also present an example of the use of INGRID (20), a program that serves as preprocessor to TOPAZ3D. Topaz programs have a feature that most other finite ele- 
ments do not have; namely, they can handle systems with internal boundary conditions which may be jump conditions. Darcy and White (21) used this feature in their work with stacked bipolar plates. To illustrate the versatility of these codes, a modified Hull cell was conceived as shown in Fig. 1. A wider range of current densities on the cathodes is made possible by slanting the bottom (with respect to the $z$ axis) of the anode $34^{\circ}$ toward the cathode.

\section{Method}

As shown by Darcy and White (21), Laplace's equation describes the steady-state potential distribution of a domain with no concentration gradients. The governing equation for the potential in the solution $\phi$ at steady-state conditions is given by

$$
\frac{\partial^{2} \phi}{\partial x^{2}}+\frac{\partial^{2} \phi}{\partial y^{2}}+\frac{\partial^{2} \phi}{\partial z^{2}}=0
$$

Assuming that no concentration gradients exist in a region $\Omega$, the current density $i$ is given by Ohm's law

$$
i=-\kappa \nabla \phi
$$

The boundary conditions at the surfaces $\Gamma_{i}$ are given by the outward normal gradient of $\phi$

$$
\boldsymbol{\kappa}_{x} \frac{\partial \phi}{\partial x} \mathbf{n}_{x}+\boldsymbol{\kappa}_{y} \frac{\partial \phi}{\partial y} \mathbf{n}_{y}+\kappa_{z} \frac{\partial \phi}{\partial z} \mathbf{n}_{z}=i_{n, \mathbf{i}}
$$

where $\mathbf{n}_{x}, \mathbf{n}_{y}$, and $\mathbf{n}_{z}$ are surface normal unit vectors, and $i_{n, \mathrm{i}}$ is the normal component of density defined by the ratio of the current that passes through $\Gamma_{\mathrm{i}}$ and the projected area of that surface segment. For insulated surfaces, $i_{n, i}$ is equal to zero.

At the electrodes the boundary condition is described by the Butler-Volmer Eq. [22]

$$
\mathbf{i}_{n, \mathrm{i}}=i_{\mathrm{o}}\left[\exp \left(\frac{\alpha_{\mathrm{a}} \mathbf{F} \boldsymbol{\eta}}{R T}\right)-\exp \left(-\frac{\alpha_{c} \mathbf{F} \eta}{R T}\right)\right]
$$

where $i_{n, \mathrm{i}}$ is the normal component of the current density vector, $i_{\mathrm{o}}$ is the exchange current density, $\mathbf{F}$ is Faraday's constant, $T$ is the absolute temperature, $\alpha_{2}$ and $\alpha_{c}$ are anodic and cathodic transfer coefficients, respectively, and $\eta$ is the activation overpotential $\left[V_{\text {solid }}(x, y, z)-\right.$ $\left.\phi_{\text {solution }}(x, y, z)\right]$. For sufficiently small activation overpotentials, Eq. [4] can be linearized to

$$
\mathbf{i}_{n, \mathrm{i}}=i_{\mathrm{o}}\left(\alpha_{\mathrm{a}}+\alpha_{\mathrm{c}}\right) \frac{\mathbf{F}}{R T} \eta
$$

By letting $\kappa=\kappa_{x}=\kappa_{y}=\kappa_{z}$, combination of Eq. [5] and [3] yields

$$
\begin{aligned}
\frac{\partial \phi}{\partial x} \mathbf{n}_{x}+\frac{\partial \phi}{\partial y} \mathbf{n}_{y}+\frac{\partial \phi}{\partial z} \mathbf{n}_{z} \\
=\frac{\left(\alpha_{\mathrm{a}}+\alpha_{\mathrm{c}}\right) i_{\mathrm{o}} \mathbf{F}}{\kappa R T}\left(V_{\text {solid }}(x, y, z)-\phi_{\text {solution }}(x, y, z)\right)
\end{aligned}
$$

The governing equations can be simplified by transforming to dimensionless parameters. Consequently to do this, let

$$
\Phi=\frac{\phi}{\phi_{\mathrm{ref}}}, \quad X=\frac{x}{t}, \quad Y=\frac{y}{t}, \quad Z=\frac{z}{t}
$$

where $\phi_{\text {ref }}$ is a reference potential and $t$ is a characteristic length chosen arbitrarily. The resulting dimensionless equations are as follows:

(i) Governing equation

$$
\frac{\partial^{2} \Phi}{\partial X^{2}}+\frac{\partial^{2} \Phi}{\partial Y^{2}}+\frac{\partial^{2} \Phi}{\partial Z^{2}}=0
$$

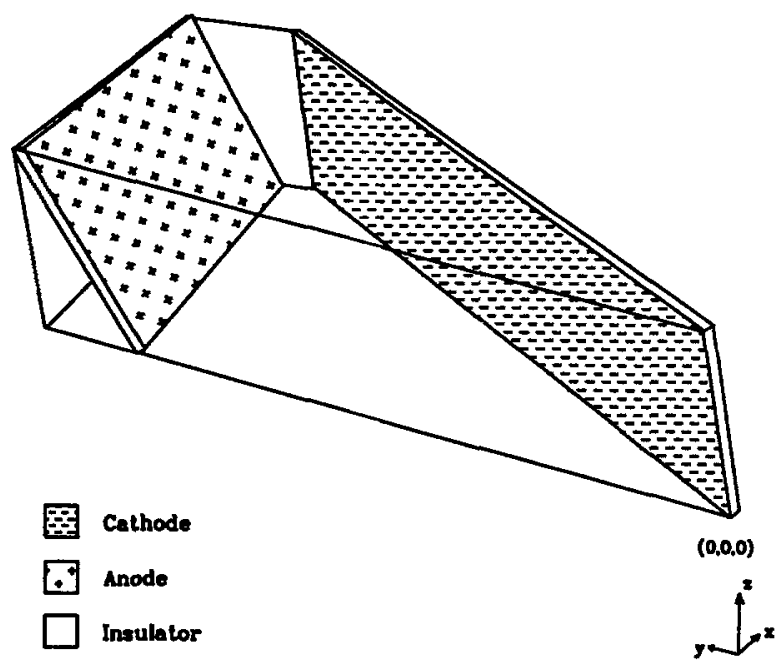

Fig. 1. Schematic of a modified Hull cell (not to scale)

(ii) Insulated boundaries

$$
\frac{\partial \Phi}{\partial X} \mathbf{n}_{x}+\frac{\partial \Phi}{\partial Y} \mathbf{n}_{y}+\frac{\partial \Phi}{\partial Z} \mathbf{n}_{z}=0
$$

(iii) Electrodes

$$
\begin{aligned}
\frac{\partial \Phi}{\partial X} \mathbf{n}_{x}+\frac{\partial \Phi}{\partial Y} \mathbf{n}_{y} & +\frac{\partial \Phi}{\partial Z} \mathbf{n}_{z} \\
& =\frac{1}{W a}\left(V_{\text {solid }}(X, Y, Z)-\Phi_{\text {solution }}(X, Y, Z)\right.
\end{aligned}
$$

where Wa is a dimensionless parameter known as the Wagner number

$$
\mathrm{Wa}=\frac{\kappa R T}{i_{\mathrm{o}} \mathrm{t} \mathbf{F}\left(\alpha_{\mathrm{a}}+\alpha_{\mathrm{c}}\right)}
$$

and is proportional to the ratio of the charge transport resistances at the surface of the electrode and through the solution. Equation [7], [8], and [9] have simple heat transfer analogues with the latter resembling a convection-type boundary condition.

\section{Results and Discussion}

Following Matlosz et al.'s work (14), the parameters in Table I were used for Wa values of 0.2 and 5.0. A system of 6800 nodes ( 5776 elements) was used to solve for potentials and current densities. The output from TOPAZ3D was modified by deleting all lines not pertaining to nodal coordinates and local current densities and the remaining data were used as input to a data postprocessor. The data postprocessor is a FORTRAN code that calculates the average current density $i_{\text {avg }}$ by taking the square root of the sum of the squares of the current density components $i_{x}, i_{y}$, and $i_{z}$ at each node. This code also calculates the current density distribution and presents the results in such a format that they can be used in a three-dimensional plotting routine. For the case at hand, the distributions were calculated along slices of the domain representing the electrode/electrolyte interfaces.

The flexibility of TOPAZ3D and INGRID was stressed by calculating the current density distributions on a modi-

Table I. Parameter values

$\begin{array}{ll}x & 0.0-6.5 \mathrm{~cm} \\ y & 0.0-12.9 \mathrm{~cm} \\ z & 0.0-6.5 \mathrm{~cm} \\ t & 8.0 \mathrm{~cm} \\ V_{\text {anode }} & 1.0 \mathrm{~V} \\ V_{\text {cathode }} & 0.0 \mathrm{~V} \\ \kappa & 0.1 \Omega^{-1} \mathrm{~cm}^{-1}\end{array}$




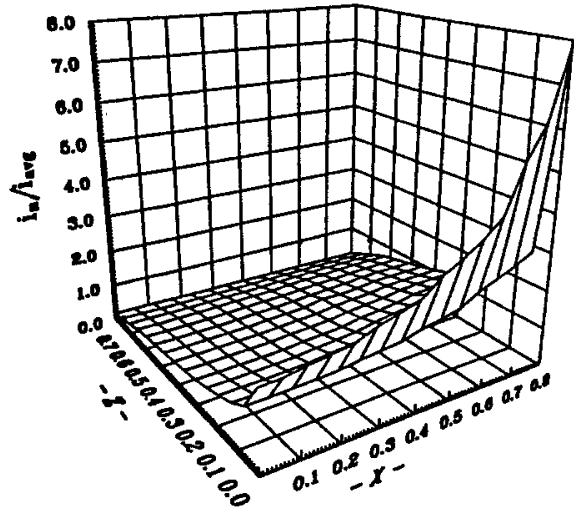

(a) tion in a modified Hull cell: (a) along the anode for $W a=0.2 ;(b)$ along the anode for $W_{a}=5.0$; (c) along the cathode for $W a=0.2$; (d) along the cathode for $W a=5.0$ with $y_{\text {ande }}=12.9 \mathrm{~cm}$ and $0 \leq y_{\text {cothode }} \leq 8.1 \mathrm{~cm}$.

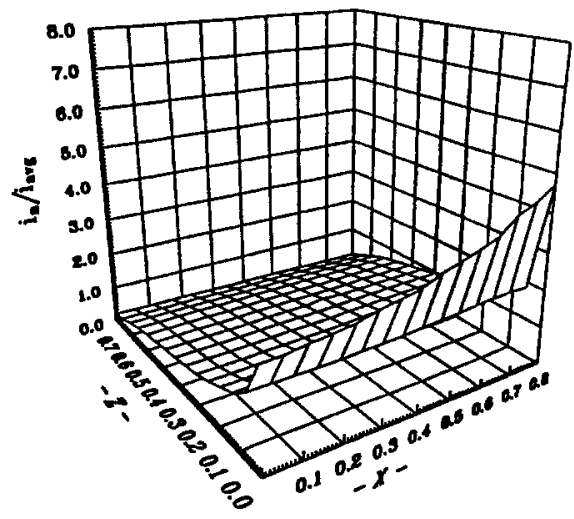

(b)
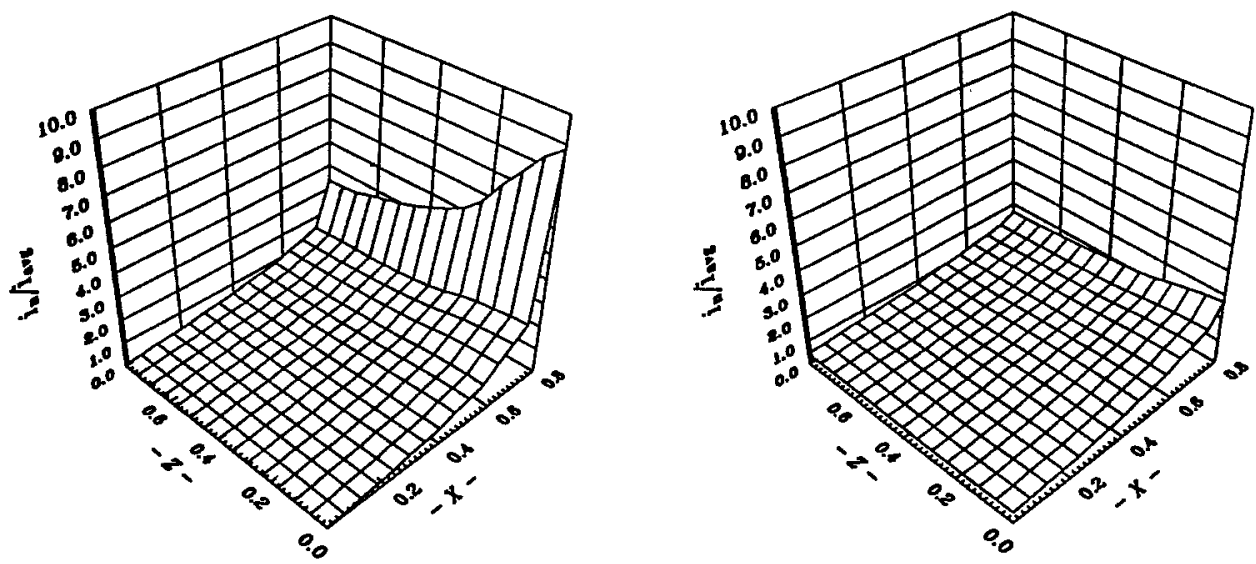

(d) fied Hull cell. In this cell, the anode was slanted toward the cathode to make an uneven gap between them. In the area of high proximity between the electrodes, the gap width varied between 0.5 and $4.8 \mathrm{~cm}$. Figure 2 presents the current density distributions for the cell of Fig. 1 and the parameters given in Table I. Following the principles given by Ibl (15) and Newman (22), for the larger Wa the distribution is more uniform and for the smaller number, a primary current distribution is approached. In the latter case the charge-transport resistance at the electrode surface (kinetic resistance) is less than the transport resistance through the solution (ohmic resistance). The larger Wa distribution tends to be more like a secondary type in which the activation overpotential is no longer negligible and the kinetic resistance is greater than the ohmic resistance $(15,22)$. As expected, a sharp increase in the current density is observed at the point of minimum gap width, even for a system with a large Wa.

In closing, TOPAZ3D could be used to study micro- and macroscale electroplating systems. More complex systems such as those fitted with interior current collectors could also be analyzed with TOPAZ3D, since the internal boundary element feature found in TOPAZ2D (17) and used by Darcy and White (21) has been recently added to TOPAZ3D.

\section{Summary}

Using dimensionless variables in the governing and boundary condition equations, the dimensionless option of TOPAZ3D can be used to predict current density distributions in electroplating systems. This was illustrated by determining the current density distributions in a modified Hull cell.

\section{Acknowledgment}

The authors are grateful for the support of this work by Texas Instruments, Incorporated.
Manuscript submitted May 4, 1989; revised manuscript received Dec. 7, 1989.

Texas A\&M University assisted in meeting the publication costs of this article.

\section{LIST OF SYMBOLS}

$T$ absolute temperature, $\mathrm{K}$

$R \quad$ universal gas constant, $8.3143 \mathrm{~J} \mathrm{~mol}^{-1} \mathrm{~K}^{-1}$

F Faraday's constant, $96,487^{\circ} \mathrm{C} /$ equiv.

$\mathbf{n}_{x}, \mathbf{n}_{y}, \mathbf{n}_{z}$ components of the surface normal unit vector,

$i \quad$ current density, $\mathrm{A} \mathrm{cm}^{-2}$

$i_{\text {avg }} \quad$ average current density, $\mathrm{A} \mathrm{cm}^{-2}$

$i_{n_{\mathrm{i}}} \quad$ normal component of the current density

through $\Gamma_{\mathrm{i}}, \mathrm{A} \mathrm{\textrm {cm } ^ { - 2 }}$

$i_{0} \quad$ exchange current density, $\mathrm{A} \mathrm{cm}^{-2}$

$t \quad$ characteristic length, $\mathrm{cm}$

$x \quad \mathrm{x}$-axis dimension, $\mathrm{cm}$

$y \quad \mathrm{y}$-axis dimension, $\mathrm{cm}$

$z \quad$ z-axis dimension, $\mathrm{cm}$

$X, Y, Z$ dimensionless distances

Greek

$\eta \quad$ activation overpotential, $\mathrm{V}$

$\eta$ potential, V

$\Phi \quad$ dimensionless potential, $\phi \phi_{\mathrm{ref}}{ }^{-1}$

$\alpha_{a}, \alpha_{c} \quad$ anodic and cathodic transfer coefficients

$\kappa_{x}, \kappa_{y}, \kappa_{z}$ specific conductivities, $\Omega^{-2} \mathrm{~cm}^{-1}$

$\Omega$ region of interest

$\Gamma_{\mathrm{i}} \quad$ surface segment $i$ on $\Omega$

\section{REFERENCES}

1. R. Morris and W. Smyrl, AIChE J., 34, 5 (1988).

2. C. Crow and R. Kasper, This Journal, 133, 5 (1986).

3. R. Munn, Mater. Perform., 29 (Aug. 1982).

4. R. Munn, Corrosion, 83, 212 (1983).

5. R. Munn, ibid., 86, 50 (1986).

6. R. Munn, ibid., 86, 46 (1986). 
7. J. Fu and S. Chan, ibid., 40, 10 (1984).

8. J. Fu and S. Chan, Mater. Perform., March, 33 (1986).

9. M. Simek and I. Rousar, J. Appl. Electrochem., 18, 96 (1988).

10. Y. Nishiki, ibid., 14, 653 (1984).

11. Y. Nishiki, ibid., 16, 291 (1986)

12. R. Alkire, T. Bergh, and R. Sani, This Journal, 125, 12 (1978).

13. L. Lee, V. Darekar, and C. Lim, IBM J. Res. Dev., 28, 6 (1984).

14. M. Matlosz, C. Creation, C. Clerc, and D. Landolt, This Journal, 134, 3015 (1987).

15. N. Ibl, "Comprehensive Treatise of Electrochemistry," Vol. 6, E. Yeager, J. Bockris, B. Conway, and S. Sarangapani, Editors, Plenum Press, New York (1983).

16. "The Canning Handbook on Electroplating," $22^{\text {nd }}$ ed., W. Canning Publishers, Birmingham (1978).
17. A. Shapiro, "TOPAZ2D; A Two Dimensional Finite Element Heat Transfer Code," UCID-20824, Mechanical Engineering Department, Lawrence Livermore National Laboratories, July (1986).

18. A. Shapiro, "TOPAZ3D; A Three Dimensional Finite Element Heat Transfer Code," UCID-20484, Mechanical Engineering Department, Lawrence Livermore National Laboratories, August (1985).

19. R. White, F. Jagush, and H. Burney, This Journal, 137, 1846 (1990).

20. D. Stillman and J. Hallquist, "INGRID; A Three Dimensional Mesh Generator for Modeling Nonlinear Systems," Lawrence Livermore National Laboratories, December (1985).

21. E. Darcy and R. White, This Journal, 135, 3 (1988).

22. J. S. Newman, "Electrochemical Systems," PrenticeHall, Inc., New York (1973).

\title{
Aluminum-Consuming Fluidized-Bed Anodes
}

\author{
Solomon Zaromb \\ Argonne National Laboratory, Environmental Research Division, Argonne, Illinois 60439 \\ C. Norman Cochran and Robert M. Mazgaj \\ Aluminum Company of America, Alcoa Laboratories, Alcoa Center, Pennsylvania 15069
}

This report summarizes and interprets the results of seven experimental runs with aluminum-chip fluidizedbed anodes performed as part of an aluminum-air battery development program at the Alcoa Technical Center. These experiments tested the feasibility of developing electrochemical power sources fueled by particulate aluminum for propulsion of electric vehicles or for supply of electric power to vital facilities in emergencies or to remote areas under routine conditions.

The reactions involved in the operation of currently developed aluminum-air batteries are [1-3]

$$
\begin{aligned}
& \text { Anode: } \mathrm{Al}+4 \mathrm{OH}^{-} \rightarrow \mathrm{Al}(\mathrm{OH})_{4}{ }^{-}+3 e^{-} \\
& \text {Cathode: } \mathrm{O}_{2}+2 \mathrm{H}_{2} \mathrm{O}+4 e^{-} \rightarrow 4 \mathrm{OH}^{-}
\end{aligned}
$$

Electrolyte regeneration: $\mathrm{Al}(\mathrm{OH})_{4}{ }^{-} \rightarrow \mathrm{Al}(\mathrm{OH})_{3}+\mathrm{OH}^{-}$

Net over-all battery reaction: $4 \mathrm{Al}+3 \mathrm{O}_{2}$

$$
+6 \mathrm{H}_{2} \mathrm{O} \rightarrow 4 \mathrm{Al}(\mathrm{OH})_{3}
$$

Competing corrosion reactions at anode:

$$
2 \mathrm{H}_{2} \mathrm{O}+2 e^{-} \rightarrow 2 \mathrm{OH}^{-}+\mathrm{H}_{2}
$$

which together with reaction [1] yields an overall parasitic reaction

$$
2 \mathrm{Al}+6 \mathrm{H}_{2} \mathrm{O}+2 \mathrm{OH}^{-} \rightarrow 2 \mathrm{Al}(\mathrm{OH})_{4}^{-}+3 \mathrm{H}_{2}
$$

Batteries of this type, in saline media, have been commercialized recently $(3,4)$. Progress has also continued in the development of alkaline Al-air batteries for the propulsion of electric vehicles $(2,4,5)$. Replenishment of the aluminum that is consumed in reaction [1] and effective removal of the $\mathrm{Al}(\mathrm{OH})_{3}$ that is formed in reaction [3] are among the main areas where further improvements are needed.

A slurry-type zinc-air power source has been reported in 1975 (6). There were also several patents issued based on the use of fluidized-bed anodes of more reactive metals (7-9). However, the use of particulate aluminum as an electrochemical fuel had not been previously demonstrated. Excessive corrosion in alkaline electrolytes and passivation in weaker media were thought to be problems.

In the following sections, the experimental results are reviewed and interpreted with emphasis on anode polarization and faradaic efficiency yield. This is followed by suggested remedies for the problems encountered in the initial experiments.

\section{Experimental Approach}

The aluminum alloys tested were either $0.0025 \mathrm{~cm}$ thick household foil containing $99.0 \% \mathrm{Al}$ (plus $0.1-0.18 \% \mathrm{Cu}$, $\leqslant 0.6 \% \mathrm{Fe}, \leqslant 0.2 \% \mathrm{Si}, \leqslant 0.05 \% \mathrm{Mn}, \leqslant 0.05 \% \mathrm{Mg}, \leqslant 0.08 \% \mathrm{Zn}$, $\leqslant 0.04 \% \mathrm{Ga}, \leqslant 0.05 \% \mathrm{Ti}$, and $<0.01 \% \mathrm{~Pb}+\mathrm{Cd}+\mathrm{As})$ or $0.025 \mathrm{~cm}$ thick $99.99 \%$ pure Al. Also, as an alternative to $0.5 \mathrm{mM}$ of $\mathrm{Pb}$ as an electrolyte additive, $0.0089 \mathrm{~cm}$ thick foil containing $99.99 \% \mathrm{Al}+6 \times 10^{-4} \% \mathrm{~Pb}$ was used in combination with $0.5 \mathrm{mM}$ each of $\mathrm{Ga}$ and In. The selected sheet or foil was sliced into chips having approximate dimensions of $0.16 \times 0.5 \mathrm{~cm}$, and a weighed amount was placed in the cell.

The electrolyte used was $6 \mathrm{~N} \mathrm{NaOH}$ or $\mathrm{KOH}$ with either of the following additives:

1. $0.5 \mathrm{mM}$ each of $\mathrm{Ga}, \mathrm{In}$, and $\mathrm{Pb}$ [which are likely to yield surface alloys previously found (10) to yield a high current density, low polarization, and low corrosion rate] or

2. $0.002 \mathrm{M}$ of $\mathrm{Hg}$ [previously found $(1,11)$ to strongly reduce corrosion of aluminum in highly alkaline solutions].

To provide a base line, the first experiments were performed without either of these additives (i.e., with pure $6 \mathrm{~N}$ $\mathrm{NaOH}$ or with $6 \mathrm{~N} \mathrm{NaOH}+0.06 \mathrm{M} \mathrm{Na}_{2} \mathrm{SnO}_{3}$ ). Except for a preliminary run, all experiments were performed directly with the fluidized anode cell shown in Fig. 1. The $1 \mathrm{~cm}$ deep anode chamber had an area of $86.7 \mathrm{~cm}^{2}$. An electrolyte diffuser (consisting of a polystyrene manifold having ten evenly spaced $3 \mathrm{~mm}$ outlet holes along the lower edge of the cell) was inserted into the bottom of the anode chamber, which lowered the effective electrode area to about $60 \mathrm{~cm}^{2}$. A no. 80 mesh nickel screen served as the anode current collector. Celgard in front of an Eltech air cathode prevented direct shorting by the aluminum particles. In runs 6 and 7 , a second anode current collector was added on the cathode side of the anode chamber in an attempt to lower the anode resistance.

Fluidization of the $0.16 \times 0.5 \mathrm{~cm}$ aluminum chips was affected by adjusting the rate of electrolyte flow through the anode compartment (using a Cole Palmer Model PB-700615 centrifugal pump in conjunction with a Variac) so that there was no agglomeration of chips near either the bottom or the top of the cell. The initial adjustment usually 